\title{
Interactive comment on "The impacts of moisture transport on drifting snow sublimation in the saltation layer” by N. Huang and X. Dai
}

\section{Anonymous Referee \#1}

\section{Received and published: 8 March 2016}

This contribution addresses an important problem, which is globally unresolved namely how much snow mass is lost back to the atmosphere during drifting and blowing snow. The contribution now tries to quantify snow sublimation in the saltation layer, which is typically regarded as insignificant because of quick saturation. The authors present a concise and well-written article, which nicely discusses her main hypothesis that continuous transport of moisture out of the saltation layer may play a significant role. However, their model assessment is fundamentally flawed and the paper must therefore be rejected. In the quantitative model assessment, the authors introduce (p.7 I.11) a completely arbitrary sink of moisture due to "advective" transport, which is contradicting the model set-up as a boundary layer model. The rest of the model uses the assumption of an equilibrium boundary layer in which forces or sinks/sources are balanced by vertical turbulent transport. By superimposing an artificial and completely unjustified 
horizontal moisture transport term, you can produce any number for sublimation. The calculation results are therefore not a scientifically sound basis for the conclusion that "DSS rate in the saltation layer can be several orders of magnitude greater than that of the suspended particles".

There are a (small) number of minor comments such as a missing discussion on surface sublimation or a splash function description on p.9 I.18, which appears to not match the corresponding equations but these are not important compared to the erroneous model set up described above.

Interactive comment on Atmos. Chem. Phys. Discuss., doi:10.5194/acp-2015-795, 2016. 